\title{
Detailed characterization of the substrate specificity of mouse wax synthase
}

\author{
Magdalena Miklaszewska, Adam Kawiński and Antoni Banaś ${ }^{\bowtie}$ \\ Intercollegiate Faculty of Biotechnology, University of Gdańsk and Medical University of Gdańsk, Gdańsk, Poland
}

\begin{abstract}
Wax synthases are membrane-associated enzymes catalysing the esterification reaction between fatty acyl-CoA and a long chain fatty alcohol. In living organisms, wax esters function as storage materials or provide protection against harmful environmental influences. In industry, they are used as ingredients for the production of lubricants, pharmaceuticals, and cosmetics. Currently the biological sources of wax esters are limited to jojoba oil. In order to establish a large-scale production of desired wax esters in transgenic high-yielding oilseed plants, enzymes involved in wax esters synthesis from different biological resources should be characterized in detail taking into consideration their substrate specificity. Therefore, this study aims at determining the substrate specificity of one of such enzymes - the mouse wax synthase. The gene encoding this enzyme was expressed heterologously in Saccharomyces cerevisiae. In the in vitro assays (using microsomal fraction from transgenic yeast), we evaluated the preferences of mouse wax synthase towards a set of combinations of 11 acyl-CoAs with 17 fatty alcohols. The highest activity was observed for 14:0-CoA, 12:0-CoA, and 16:0-CoA in combination with medium chain alcohols (up to $5.2,3.4$, and $3.3 \mathrm{nmol}$ wax esters $/ \mathrm{min} / \mathrm{mg}$ microsomal protein, respectively). Unsaturated alcohols longer than $18^{\circ} \mathrm{C}$ were better utilized by the enzyme in comparison to the saturated ones. Combinations of all tested alcohols with 20:0-CoA, 22:1-CoA, or Ric-CoA were poorly utilized by the enzyme, and conjugated acyl-CoAs were not utilized at all. Apart from the wax synthase activity, mouse wax synthase also exhibited a very low acyl-CoA:diacylglycerol acyltransferase activity. However, it displayed neither acyl-CoA:monoacylglycerol acyltransferase, nor acylCoA:sterol acyltransferase activity.
\end{abstract}

Key words: wax esters, lipids, fatty alcohols, acyl-CoA

Received: 08 February, 2013; revised: 25 April, 2013; accepted: 14 May, 2013; available on-line: 31 May, 2013

\section{INTRODUCTION}

Wax esters are esters of long chain fatty alcohols and fatty acids produced by a wide variety of organisms, including microorganisms, plants, and animals. In plants, they are components of cuticles. In mammals, wax esters constitute approximately $30 \%$ of sebum. In Simmondsia chinensis (jojoba), wax esters are accumulated as seed storage lipids, instead of triacylglycerols (Lassner et al., 1999). They are used to produce high-pressure lubricants and for other purposes in the pharmaceutical, cosmetic, printing, and leather industries (Klypina \& Hanson, 2008).
Apart from chemical synthesis, the only renewable source of wax esters is, so far, jojoba oil. However, due to the high cost of wax ester production in jojoba farms, as well as an unfavourable blend of very long chain wax esters in this oil making it not suitable for technical application (Miwa, 1971), there is an increasing demand for alternative and renewable sources of these compounds. It was shown that seeds of Arabidopsis transformed with a plasmid carrying an elongase ( $\beta$-ketoacyl-CoA synthase, KCS) from Lunaria annua, as well as wax synthase (WS) and fatty acyl-CoA reductase (FAR) from S. chinensis, contained significant amounts of wax esters (Lardizabal et al., 2000; Lassner et al., 1999). Similar results were obtained when these genes were expressed in Camelina sativa ( $\mathrm{Lu}$ et al., 2010), which suggests that modification of oilseed crops using genes of enzymes involved in wax esters biosynthesis might be a way of obtaining a new, renewable source of different kinds of wax esters. In order to generate new types of wax esters in transgenic high-yielding oilseed plants, the substrate specificity of the enzymes involved in wax esters synthesis (FARs and WSs) from different biological resources should be characterized in detail, in order to provide plant biotechnologists with tools to direct lipid metabolism in oilseed plants towards the production of desired wax esters.

The biosynthetic pathway of wax esters in plants starts in plastids, from which fatty acids (converted to acyl-CoAs in the outer membrane of plastids) are transported to cytosol, where they can be elongated to longer acyl-CoAs by the fatty acid elongases system. Acyl-CoAs are then reduced, by alcohol forming fatty acyl-CoA reductase, to corresponding alcohols. The final reaction of the wax esters synthesis is carried out by wax synthase, which catalyzes the esterification reaction of the fatty acyl-CoA with a long chain fatty alcohol (Lardizabal et al., 2000).

Wax synthases are membrane-associated enzymes with several transmembrane domains. Genes of several wax

\section{e-mail: banas@biotech.ug.gda.pl}

Abbreviations: WS, wax synthase, fatty acyl-CoA:fatty alcohol acyltransferase; FAR, fatty acyl-CoA reductase; DGAT, acyl-CoA:diacylglycerol acyltransferase; MAGAT, acylCoA:monoacylglycerol acyltransferase; ASAT, acyl-CoA:sterol acyltransferase; DAG diacylglycerol; TAG, triacylglycerol; 10:0, decanoic acid (capric acid); $10: 0-0 \mathrm{H}$, decanol; 12:0, dodecanoic acid (lauric acid); 12:0-0H, dodecanol; 14:0, tetradecanoic acid (myristic acid); 14:0-0H, tetradecanol; 16:0, hexadecanoic acid (palmitic acid); 16:0$0 \mathrm{H}$, hexadecanol; 18:0, octadecanoic acid (stearic acid); 18:0-0H, octadecanol; 18:1, oleic acid; 18:1-0H, octadecenol; 18:2, linoleic acid; 18:2-0H, linoleyl alcohol; 18:3, linolenic acid; $18: 3-0 \mathrm{H}$, linolenyl alcohol; 20:0, eicosanoic acid (arachidic acid); 20:0-0H, eicosanol; 22:1, erucic acid; 20:1-0H, eicosenol; 22:1-0H, docosenol; 24:0-0H, tetracosanol; 24:1-0H, tetracosenol; Ric, ricinoleic acid; Ric-OH, ricinoleoyl alcohol; 2-Me-16:0, 2-methylhexadecanoic acid; 2-Me18:0, 2-methyloctadecanoic acid. 
synthases from different organism have been cloned and the expressed enzymes were, at least partially, characterized, e.g. from: human and mouse (Cheng \& Russel, 2004), jojoba (Lardizabal et al., 2000), Arabidopsis (Li et al., 2008), Euglena gracilis (Teerawanichpan \& Qiu, 2010), Marinobacter hydrocarbonoclasticus (Holtzapple \& SchmidtDannert, 2007), and Acinetobacter calcoaceticus (Kalscheuer \& Steinbüchel, 2003). Few wax synthases were reported to be bifunctional enzymes (e.g. Acinetobacter, Arabidopsis), additionally exhibiting a DGAT activity (Stöveken $e t$ al., 2005).

Wax synthase from a mouse is a 333-amino-acid protein with three putative transmembrane domains (based on the sequence analysis available in UniProtKB; Q6E1M8), located in the membranes of the endoplasmic reticulum. The enzyme gene is located on the chromosome X, band C3 (100402221-100442717 bp). Mouse wax synthase is involved in the synthesis of wax monoesters, which are major components of sebum and meibum. The highest level of its mRNA was observed in the preputial gland and eyelid. In vitro assays showed that mouse wax synthase expressed in HEK 293 cells is able to synthesize wax esters from different fatty alcohols and acyl-CoAs. However, the quantitative analysis of the obtained products was not performed (Cheng \& Russel, 2004).

In order to predict the usefulness of mouse wax synthase for the production of specific types of wax esters in transgenic high-yielding oilseed plants, the substrate specificity of the enzyme was characterized in detail. The gene encoding mouse wax synthase was expressed heterologously in Saccharomyces cerevisiae, strain H1246, deficient in enzymes involved in triacylglycerols and sterol esters synthesis. Subsequently, the preferences of mouse wax synthases towards different combinations of fatty acylCoAs and fatty alcohols were tested in in vivo and in vitro experiments.

\section{MATERIALS AND METHODS}

Heterologous expression of mouse WS in Saccharomyces cerevisiae. Saccharomyces cerevisiae, strain H1246 (Sandagar et al., 2002), was transformed with the pBP51 (pYES2) plasmid carrying the mouse WS gene under the control of GAL1 promoter or with an empty pYES2 plasmid (control), according to the modified LiAc/SS carrier DNA/PEG method (Gietz \& Woods, 2002). The sequence of mouse WS gene was codon optimized for expression in Brassicaceae (Heilmann et al., 2012). The yeasts were cultured on a synthetic dropout medium lacking uracil and containing $2 \%(\mathrm{w} / \mathrm{v})$ galactose for the selection of transformants.

Yeast growth and lipid analysis. Yeasts (transformed with mouse WS or with an empty plasmid) were cultured on a rotating platform $(220 \mathrm{rpm})$ at $30^{\circ} \mathrm{C}$, for $48 \mathrm{~h}$, on $25 \mathrm{ml}$ of synthetic dropout medium lacking uracil and containing: $2 \%(\mathrm{w} / \mathrm{v})$ galactose, $1 \%(\mathrm{v} / \mathrm{v})$ Tween 20, and $12.5 \mathrm{mg}$ of palmitoleic alcohol. Cells harvested from individual cultures were disrupted in a glass-bead shaker, and lipids were extracted into chloroform, as described by Blight \& Dyer (1959), and separated by thin-layer chromatography (TLC) on silica gel 60 plates (Merck, New York, USA) using hexane/diethyl ether/acetic acid (70/30/1, v/v/v) as the solvent system. The lipid areas were visualized by brief exposure to $I_{2}$ vapours and identified by means of appropriate standards. The parts of silica gels containing wax esters and other lipids were collected from the plates. In order to obtain fatty acid methyl esters, the dry, collected material was trans-methylated with $2 \%(\mathrm{v} / \mathrm{v})$ sulphuric acid in dry methanol at $90^{\circ} \mathrm{C}$ for $40 \mathrm{~min}$. The methyl esters were extracted with hexane and analysed by means of the Shimadzu GC-2010 equipped with a flame ionization detector and a $60 \mathrm{~m} \times 0.25 \mathrm{~mm}$ CP-WAX $58 \mathrm{CB}$ fused-silica column (Agilent Technologies, Santa Clara, CA, USA). Methyl ester of heptadecanoic acid (Sigma-Aldrich, St. Louis, MO, USA) was used as an internal standard. Total fatty acids in the acyl-lipids of the analysed yeast were determined by gas chromatography after prior incubation of freeze-dried yeast aliquots with a methylation mixture for $90 \mathrm{~min}$ at $90^{\circ} \mathrm{C}$.

Microsomal membrane preparation. Microsomes were isolated from the yeast using the method described in Dahlqvist et al. (2000). For a single preparation of microsomal fractions, $100 \mathrm{ml}$ of a 48 -h yeast culture was centrifuged and washed twice with distilled water, and the pellet was suspended in $0.5 \mathrm{ml}$ of ice-cold buffer $(20$ $\mathrm{mM}$ Tris/HCl, pH 7.9; $10 \mathrm{mM} \mathrm{MgCl}$. $1 \mathrm{mM}$ EDTA; $5 \% \quad(\mathrm{v} / \mathrm{v})$ glycerol; $0.3 \mathrm{M}$ ammonium sulphate) and transferred to a $2 \mathrm{ml}$ test tube containing $0.5-\mathrm{ml}$ glass beads $(0.45-0.50 \mathrm{~mm}$ in diameter). The tube was shaken (10 times, $30 \mathrm{~s}$ ) using the Mini Bead Beater-8 (Biospec Products, Bartlesville, OK, USA). After that, the yeasts were centrifuged at $1500 \times \mathrm{g}$ for $10 \mathrm{~min}$ at $4^{\circ} \mathrm{C}$, and the resulting supernatant was centrifuged at $100000 \times g$ for 1.5 hour at $4^{\circ} \mathrm{C}$. The pellet was suspended in $0.1 \mathrm{M}$ potassium buffer $\left(\mathrm{pH}\right.$ 6.7) and stored at $-80^{\circ} \mathrm{C}$ until use for further analyses.

Enzyme assays. In the experiments aiming at optimization of the in vitro assays and biochemical characterization of the tested enzyme, all reactions were performed using $\left[1-{ }^{14} \mathrm{C}\right] 16: 0-\mathrm{CoA}$ and $16: 0-\mathrm{OH}$ as substrates. A detailed study of the substrate specificity of mouse wax synthase was performed with eleven $\left[1-{ }^{14} \mathrm{C}\right]$ acyl-CoAs in combination with seventeen unlabeled fatty alcohols (Table 1). The $\left[1-{ }^{14} \mathrm{C}\right]$ acyl-CoAs were synthesized using $\left[1-{ }^{14} \mathrm{C}\right]$ fatty acids (Biotrend, Cologne, Germany) according to the modified method described by (Sánchez et al., 1973). Unlabelled acyl-CoAs were purchased from Avanti Polar Lipids (Alabaster, AL, USA). The tested fatty alcohols (except phytol) were purchased from Larodan

Table 1. Fatty alcohols and acyl-CoAs used in the assays.

\begin{tabular}{|c|c|c|c|c|c|c|}
\hline & 10:0-0H & $12: 0-0 \mathrm{H}$ & $14: 0-0 \mathrm{H}$ & $16: 0-0 \mathrm{H}$ & $16: 1-0 \mathrm{H}$ & 18:0-0H \\
\hline \multirow[t]{3}{*}{ Fatty alcohols } & 18:1-0H & $18: 2-0 \mathrm{H}$ & $18: 3-0 \mathrm{H}$ & $20: 0-0 \mathrm{H}$ & $20: 1-0 \mathrm{H}$ & $22: 0-0 \mathrm{H}$ \\
\hline & $22: 1-0 \mathrm{H}$ & 24:0-0H & $24: 1-0 \mathrm{H}$ & Ric-OH & phytol & \\
\hline & $12: 0-\mathrm{CoA}$ & 14:0-CoA & 16:0-CoA & 18:0-CoA & 18:1-CoA & $22: 1-\mathrm{CoA}$ \\
\hline \multirow[t]{2}{*}{ Acyl-CoAs } & $\begin{array}{l}{[1-14 \mathrm{C}]} \\
10: 0-\mathrm{CoA}\end{array}$ & $\begin{array}{l}{[1-14 \mathrm{C}]} \\
12: 0-\mathrm{CoA}\end{array}$ & $\begin{array}{l}{[1-14 \mathrm{C}]} \\
14: 0-\mathrm{CoA}\end{array}$ & $\begin{array}{l}{[1-14 \mathrm{C}]} \\
16: 0-\mathrm{CoA}\end{array}$ & $\begin{array}{l}{[1-14 \mathrm{C}]} \\
18: 0-\mathrm{CoA}\end{array}$ & $\begin{array}{l}{[1-14 \mathrm{C}]} \\
18: 1-\mathrm{CoA}\end{array}$ \\
\hline & $\begin{array}{l}{[1-14 \mathrm{C}]} \\
20: 0-\mathrm{CoA}\end{array}$ & $\begin{array}{l}{[1-14 \mathrm{C}]} \\
22: 1-\mathrm{CoA}\end{array}$ & $\begin{array}{l}{[1-14 \mathrm{C}]} \\
\text { Ric-CoA }\end{array}$ & $\begin{array}{l}{[1-14 \mathrm{C}]} \\
2-\mathrm{Me}-16: 0-\mathrm{CoA}\end{array}$ & $\begin{array}{l}{[1-14 \mathrm{C}]} \\
2-\mathrm{Me}-18: 0-\mathrm{CoA}\end{array}$ & \\
\hline
\end{tabular}


Fine Chemicals (Malmö, Sweden), and phytol was purchased from Sigma-Aldrich (St. Louis, MO, USA).

In the preliminary experiments, enzyme assays were conducted using either alcohols (different amounts) added with ethanol $(10 \mu \mathrm{l})$ to the microsomal fraction (22 $\mu \mathrm{g}$ of protein) resuspended in a 100- $\mu$ l buffer (different $\mathrm{pH}$ ) with BSA (different concentrations) and acyl-CoA (5 nmol), or alcohols added with $20-\mu 1$ benzene to the freeze-dried microsomal fraction. In the latter case, benzene was immediately evaporated under a stream of $\mathrm{N}_{2}$ at $35^{\circ} \mathrm{C}$ leaving the alcohols in direct contact with the membrane, after which a buffer (composition described above) was added. Microsomes were incubated (different time and temperature) in the Eppendorf Thermomixer Compact with shaking (1250 $\mathrm{rpm})$. Reactions were terminated by the addition of $375-\mu$ l chloroform/methanol $(1: 2 ; \mathrm{v} / \mathrm{v})$, $5-\mu \mathrm{l}$ acetic acid, $125-\mu \mathrm{l}$ chloroform, and 125- $\mu \mathrm{l}$ water, and the lipids were extracted into chloroform. After the optimization step, fatty alcohols (100 nmol/assay) were added to the freeze-dried microsomal membrane (22 $\mu \mathrm{g}$ of protein) in a benzene solution. As an incubation buffer, we used $0.1 \mathrm{ml}$ p-buffer ( $\mathrm{pH}$ 6.7) with $0.2 \mathrm{mg} \mathrm{BSA}$ and $5 \mathrm{nmol}$ of a tested $\left[1-{ }^{14} \mathrm{C}\right]$ acyl-CoA. Microsomes were incubated for $30 \mathrm{~min}$ at $35^{\circ} \mathrm{C}$ with shaking $(1250 \mathrm{rpm})$. In some of the experiments, instead of a single acyl-CoA, we added to the reaction a mixture of six different acyl-CoAs: 12:0-CoA, 14:0CoA, 16:0-CoA, 18:0-CoA, 18:1-CoA, and 22:1-CoA (1 nmol of each), among which only one was radiolabelled. All other conditions were maintained as described above.

Assays measuring the DGAT activity in the control and carrying tested mouse WS microsomal fractions were performed with 1,2-dihexanoyl-sn glycerol (Sigma-Aldrich, St. Louis, MO, USA) or 1,2-[1-14C]-dioleoyl-sn glycerol, as acyl acceptors, as well as different acyl-CoAs as acyl donors. MAGAT and ASAT activity in the tested microsomal fraction was measured using 1-[1-14C]oleoyl-sn glycerol and cholesterol (Sigma-Aldrich, St. Louis, MO, USA), respectively, as acyl acceptors, and 14:0-CoA, 16:0-CoA 18:1-CoA, and 22:1-CoA, as acyl donors (in assays with cholesterol, [1-14C]acylCoAs were used as acyl donors). 1,2-[1-14C C]-dioleoyl-sn glycerol and 1-[1-14C]oleoyl-sn glycerol were obtained by partial treatment of $\left[1-{ }^{14} \mathrm{C}\right]$-triolein (Perkin Elmer, Waltham, MA, USA) with a lipase from Rhizopus arrbizus (Sigma-Aldrich, St. Louis, MO, USA). 1,2-[1-14C]-dioleoyl-sn glycerol, 1-[1-14C]-oleoyl-sn glycerol, and cholesterol were added ( $5 \mathrm{nmol} /$ assay) to the freeze-dried microsomal fraction ( $22 \mu \mathrm{g}$ microsomal protein) in a benzene solution (method described above). The incubation buffer $(100 \mu \mathrm{l} 0.05 \mathrm{M}$ Hepes, pH 7.2 per assay) containing $20 \mathrm{mM} \mathrm{MgCl}, 0.1 \mathrm{mg}$ BSA and $5 \mathrm{nmol}$ of proper acyl-CoA was added to the microsomes carrying the added acceptors (in DGAT assays with soluble 1,2-dihexanoyl-sn glycerol, microsomes were added to the buffer), the mixtures were incubated, and the reactions were terminated in the same way as described above for wax synthase activity assays.

After termination of the reactions, lipids extracted to the chloroform were separated by TLC on silica gel 60 plates (Merck, New York, USA) using hexane/diethyl ether/acetic acid $(70 / 30 / 1, \mathrm{v} / \mathrm{v} / \mathrm{v})$, as the solvent system. Radiolabelled lipids were visualised and quantified on the plates by electronic autoradiography (Instant Imager, Packard Instrument Co., Meriden, CT, USA).

All assays were repeated at least three times. Results are presented as the mean with standard deviation.

\section{RESULTS}

\section{Evaluation of the effects of transformation of yeast with mouse WS}

Mouse WS was cloned into S. cerevisiae H1246 strain, which lacks genes involved in triacylglycerols and sterol esters synthesis (Sandagar et al., 2002). Thus, no endogenous sterol esters, which usually co-migrate together with wax esters during lipid separation by TLC, were present in the lipid extract from such yeast cultures. Therefore, the effect of transformation could be easily confirmed by feeding the yeast with exogenous fatty alcohols and analysing the production of wax esters, separated from other lipids by TLC (wax esters migrated to the top of the plate when: hexane/DEE/acetic acid - 70/30/1 $\mathrm{v} / \mathrm{v} / \mathrm{v}$ - was used as the solvent system). It turned out that all of the transformed yeast colonies produced wax esters, however, not with the same intensity (data not shown). The amount of wax esters extracted from the colony with the highest in vivo enzyme activity accounted for about $21 \%$ of total lipids. The fatty acid component of the produced wax esters contained mainly palmitoleic acid, palmitic acid, oleic acid, and myristic acid (Table 2).

\section{Influence of different factors on the in vitro activity of mouse WS}

Before starting the detailed study on the substrate specificity of mouse WS, we established the assay conditions and determined the biochemical characteristics of the enzyme. For the assays, we used microsomal fractions isolated from the yeast expressing the mouse WS gene (the colony with the highest activity of the tested enzyme). As mouse WS is located in membranes of the endoplasmic reticulum, purification of such an enzyme is associated with significant difficulties and very seldom brings success. Therefore, we decided to use microsomal fractions from yeast cells transformed with mouse wax synthase gene, enriched with this enzyme. The microsomal fractions from control yeasts did not demonstrate any detectable wax synthase activity (data not presented). Thus, the method applied to determine the substrate specificity of mouse WS seems to be the best solution taking into consideration the unavailability of the pure enzyme.

In the preliminary experiments, it was observed that the enzyme showed a very strong activity towards 16:0CoA combined with 16:0-OH. Therefore, this combination of substrates was chosen for most of the further assays. The way fatty alcohols were added to the assays was crucial for successful measurement of the in vitro activity of mouse WS. It turned out that the best way to supplement the reaction mixtures with fatty alcohols was to add these compounds in a benzene solution to freeze-dried microsomal fractions, and to immediately evaporate the benzene (this method was introduced to the assays of enzymes utilizing hydrophobic substrates by prof. Sten Stymne group from the Swedish University of Agricultural Science: Banas et al. 2000; Dahlqvist et al. 2000; Ståhl et al. 2004). Thus, the fatty alcohols penetrated the microsomal membranes, and after benzene evaporation, remained in direct contact with the membranes. Addition of fatty alcohols to the reaction mixture in ethanol solution (methods used in earlier experiments described by Cheng \& Russel, 2004) was less efficient, especially in case of saturated (longer than 16 carbons) and unsaturated (longer than 20 carbons) fatty alcohols (not shown). 


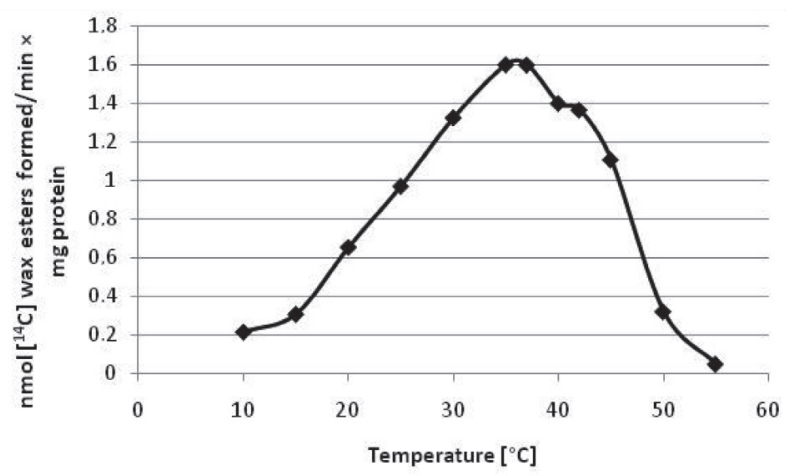

Figure 1. Temperature dependency of mouse WS activity. $16: 0-\mathrm{OH}$ and 16:0-CoA were used as substrates in the assays.

Temperature is one of the most crucial environmental factors affecting enzyme activity. In the presented experiments, we tested mouse WS activity at temperatures ranging from $10^{\circ} \mathrm{C}$ to $55^{\circ} \mathrm{C}$. The enzyme activity was low at $10^{\circ} \mathrm{C}$ and was gradually increasing at temperatures reaching up to $35^{\circ} \mathrm{C}$. Above $35^{\circ} \mathrm{C}$, its level was stable and remained more or less similar at temperatures up to $37^{\circ} \mathrm{C}$. Further increase of the temperature up to $43^{\circ} \mathrm{C}$ slightly decreased the mouse WS activity, however, above that point the activity decreased radically and almost ceased at $55^{\circ} \mathrm{C}$ (Fig. 1). Another environmental factor affecting enzymes activity is $\mathrm{pH}$. In this study the effects of $\mathrm{pH}$ between 4 and 10 were investigated. $\mathrm{pH}$ 4-6 was obtained with citrate buffer, $\mathrm{pH}$ 6-8 with p-buffer, and

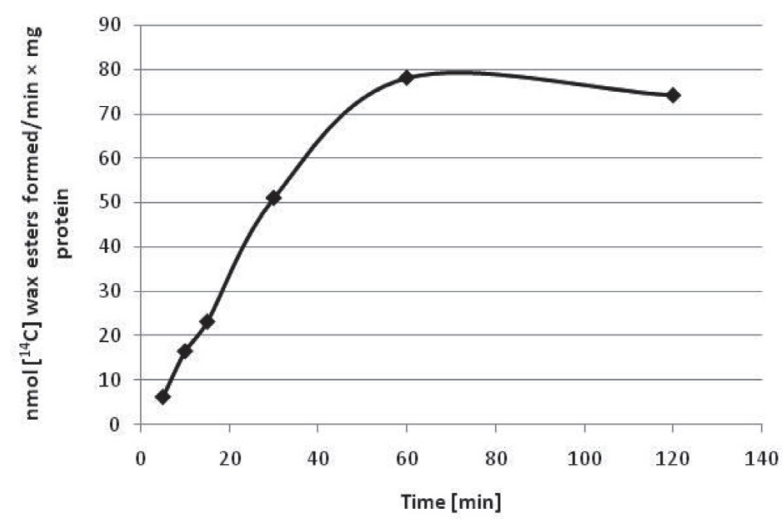

Figure 2. Time dependency of the reaction rate of wax ester synthesis catalysed by mouse WS.

16:0-OH and 16:0-CoA were used as substrates in the assays.

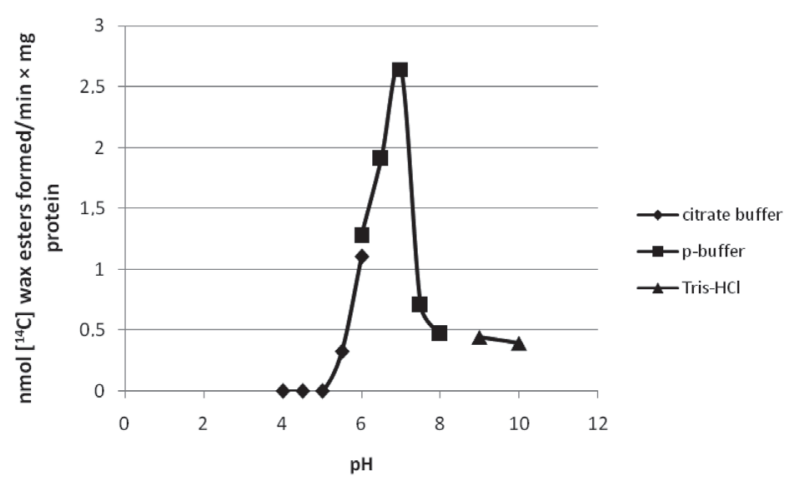

Figure 3. pH dependency of mouse WS activity.

$16: 0-\mathrm{OH}$ and 16:0-CoA were used as substrates in the assays.
$\mathrm{pH}$ 9-10 with Tris/HCl buffer. The enzyme was completely inactive at $\mathrm{pH} 4$ to 5 , and above that level its activity gradually increased reaching the maximum at $\mathrm{pH}$ around 7 . The increase of $\mathrm{pH}$ just to 7.5 caused a radical decrease of the enzyme activity to about $1 / 4$ of its maximum value. Further increases of $\mathrm{pH}$ (up to 10) resulted in a slight decrease of mouse WS activity. In case of $\mathrm{pH}$ 6 , the enzyme produced a higher amount of wax esters in p-buffer than in citrate buffer (Fig. 3). At the optimal assay conditions $(22 \mu \mathrm{g}$ of microsomal protein, 100 nmol 16:0-OH, 5 nmol 16:0-CoA, pH 6.7, 35 C, $100 \mu \mathrm{l}$ incubation buffer), the rate of the reaction catalysed by mouse WS rose linearly up to $30 \mathrm{~min}$ (Fig. 2). The reaction rate reached a plateau after $60 \mathrm{~min}$.

\section{Substrate specificity of mouse WS}

Assay conditions optimized as described above, were used for detailed studies on the substrate specificity of mouse WS. To determine the preferences of the tested enzyme for different combinations of acyl-CoAs and fatty alcohols, 11 radiolabelled acyl-CoAs in combination with 17 fatty alcohols were tested (together 187 combinations; Table 1). It turned out that the enzyme did not accept the tested combinations of the substrates in the same way, and that the acyl-CoA component was crucial for the enzyme activity. The alcohol component also had a certain effect, however, much weaker than the fatty acid component (Fig. 4-6). For example, when 14:0-CoA was combined with 10:0-OH, the enzyme produced around $3.9 \mathrm{nmol}$ of 14:0-10:0 WE/min $/ \mathrm{mg}$ microsomal protein, whereas when 10:0-CoA was combined with 14:0-OH - only around $1.2 \mathrm{nmol}$ of 10:014:0 WE/min/mg microsomal protein (Fig. 4). The best efficiency of mouse WS was observed for the combinations of tested alcohols with 14:0-CoA. In most of the combinations with tested alcohols, the enzyme was able to synthesize around $3 \mathrm{nmol} \mathrm{WE} / \mathrm{min} / \mathrm{mg}$ microsomal proteins or more (up to $5.2 \mathrm{nmol} / \mathrm{min} / \mathrm{mg}$ microsomal protein when 14:0-CoA was combined with 14:0-OH). Only when 14:0-CoA was combined with long chain saturated alcohols (20C or longer), the enzyme efficiency was low (Fig. 4). The second most efficiently utilized (by mouse WS) acyl-CoA was 12:0-CoA, followed by 16:0CoA, 18:1-CoA, 18:0-CoA, and 10:0-CoA (Fig. 4-6). The effect of fatty alcohols used in combinations with mentioned acyl-CoAs was slightly similar to the effect described for 14:0-CoA. In general, unsaturated fatty alcohols longer than 18C were better utilized than the saturated ones. In case of $18 \mathrm{C}$ alcohols, the degree of unsaturation did not affect the enzyme activity (application of $18: 1-\mathrm{OH}, 18: 2-\mathrm{OH}$, or $18: 3-\mathrm{OH}$ in the assays produced similar results). Comparison of the enzyme efficiency towards 18:0-CoA and 18:1-CoA suggests that also the unsaturation of the acyl component results in a higher mouse WS activity (Fig. 5, 6). Combinations of all the tested alcohols with 20:0-CoA, 22:1-CoA, or Ric-CoA were poorly utilized by the enzyme (Fig. 5, 6). No wax ester production was observed when we used the conjugated acyl-CoAs (2-Me-16:0-CoA and 2-Me18:0-CoA) in combination with any of the alcohols (not shown).

In order to verify if mouse WS preferences for acylCoAs differ when acyl-CoA is added to the reaction mixture alone (like described above), compared to the situation when it is added to the reaction mixture with other acyl-CoAs, combinations of six acyl-CoAs (12:0CoA, 14:0-CoA, 16:0-CoA, 18:0-CoA, 18:1-CoA, 22:1$\mathrm{CoA}$ ) with 16:0-OH were tested. It turned out that en- 


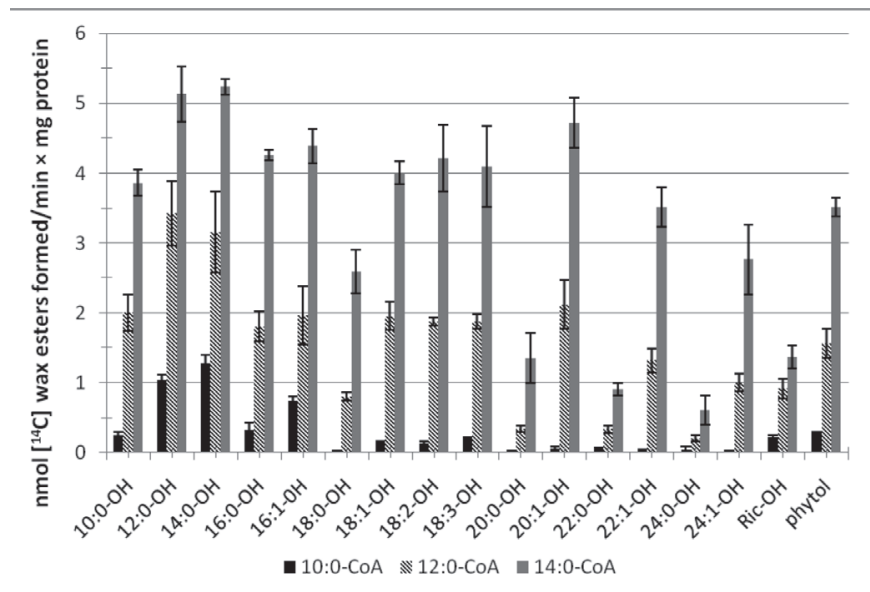

Figure 4. Activity of mouse WS towards 10:0-CoA, 12:0-CoA, and 14:0$\mathrm{COA}$ in combination with 17 different fatty alcohols.

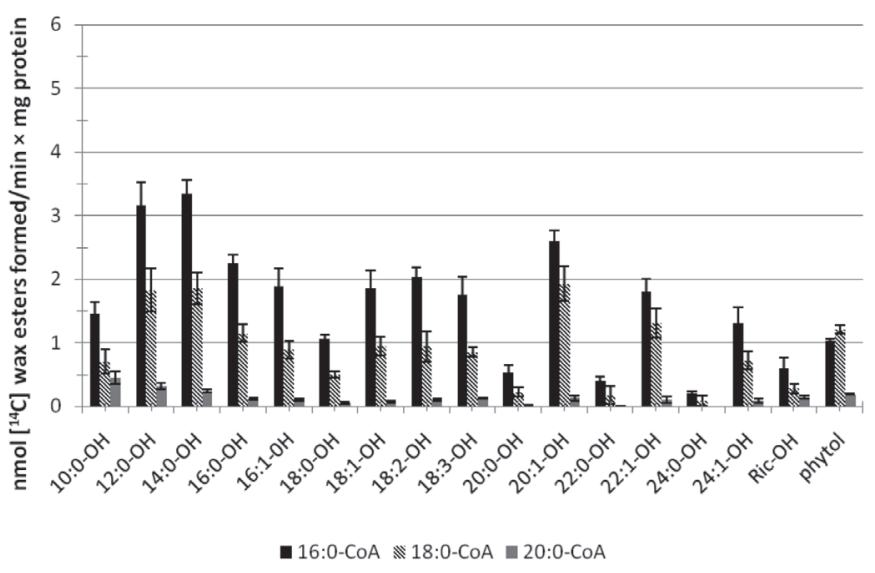

Figure 5. Activity of mouse WS towards 16:0-CoA, 18:0-CoA, and 20:0$\mathrm{COA}$ in combination with 17 different fatty alcohols.

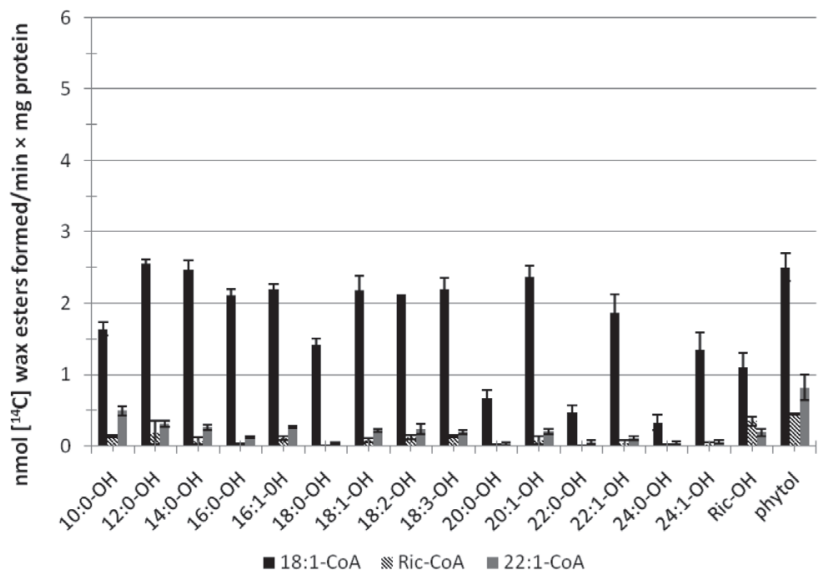

Figure 6. Activity of mouse WS towards 18:1-CoA, 22:1-CoA, and RicCoA in combination with 17 different fatty alcohols.

zyme preferences for a given acyl-CoA were independent from the way acyl-CoA was added (as a single substrate or in mixture with other acyl-CoAs), (Fig. 7). Thus, the results obtained in the assays in which combinations of a single acyl-CoA with a single fatty alcohol were used could be considered as a proxy for the results obtained for the mixture of acyl-CoAs (most common situation occuring in nature). However, it should be noted that in case of the mixture of medium and long chain acyl-CoAs, acyl-CoAs with medium chain length could be a bit better utilized than those with longer chain lengths, as compared to the situation in which a single acyl-CoA is added to the reaction buffer.

Apart from the wax esters synthase activity, only the DGAT activity was elevated in the tested microsomal fraction enriched with mouse wax synthase, compared to the assays with control microsomes in in vitro experiments. However, the DGAT activity in microsomal fraction enriched with mouse WS was negligible - only slightly higher than the residual DGAT activity in the microsomal preparation from the yeast transformed with an empty plasmid (Table 2 and data not presented). In the assays with $\left[{ }^{14} \mathrm{C}\right] 18: 1-\mathrm{MAG}$ and acyl-CoA, not even trace amounts of de novo synthesized $\left[{ }^{14} \mathrm{C}\right] \mathrm{DAG}$ were observed. Thus, the results strongly suggest that mouse WS does not possess a MAGAT activity. Similar observations concerning the ASAT activity of mouse WS were obtained in the assays with $\left[{ }^{14} \mathrm{C}\right]$ acyl-CoA and cholesterol. No trace of de novo synthesized $\left[{ }^{14} \mathrm{C}\right]-$ sterol esters was observed (not shown).

\section{DISCUSSION}

The design of a biotechnological process of wax esters production in living organism will be based on a proper selection of enzymes displaying desired specificity, which will enable the production of wax esters of certain structures and features. The composition of wax esters produced by the organism from which the wax synthase was used for cloning does not fully describe the substrate specificity of this enzyme. The final composition of produced wax esters depends not only on the properties of the enzyme, which catalyses the synthesis of wax esters, but also on the availability of acyl-CoAs and fatty alcohols. Thus, to get a full picture of the substrate specificity of a given wax synthase, in vitro assays are necessary. For such studies, bacteria, yeast, or cell cultures expressing genes of the studied enzymes are usually utilized. Proper choice of the model organism is very important in order for the experiments to be successful. It appeared that for the substrate specificity studies of mouse wax synthase, the H1246 yeast (Saccharomyces cerevisiae) strain is a very good model system. They do not produce their own wax esters (Sandagar et al., 2002), so the substrate specificity can be studied both in vivo and in vitro. Additionally, the expression level of the tested enzyme was sufficient to obtain a microsomal fraction with high wax synthase activity. Yeasts were also successfully used in other studies on wax synthase substrate specificity (Li et al., 2008; Teerawanichpan \& Qiu, 2010; Biester et al., 2012; Shi et al., 2012), and therefore they could be recommended for further studies of similar enzymes.

The presented in vitro assays strongly suggest that mouse wax synthase is most suitable for the synthesis of medium chain wax esters, especially with 14:0-FA, as fatty acid components. On the other hand, the enzyme seems to be completely useless for the production of wax esters 


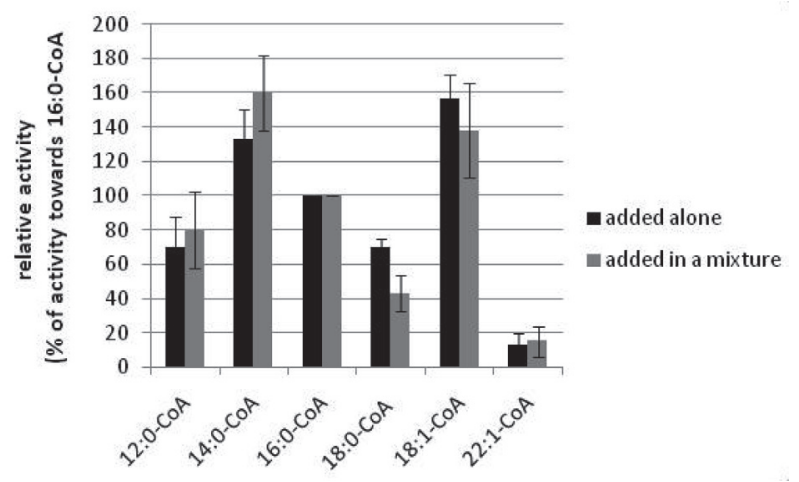

Figure 7. Activity of mouse WS towards six acyl-CoA added (together with 16:0-OH) as single acyl-CoA or as a mixture of six acyl-CoA to the assays.

with conjugated fatty acids (data not presented), fatty acids longer than 18C, or ricinoleic acid (Fig. 5 \& 6). Fatty alcohols seem to have a smaller influence on the enzyme activity, however, unsaturated alcohols with chains longer than 18C are better utilized than their saturated counterparts. The results obtained in vivo support the results of the in vitro study, especially with regard to the extremely high preferences of mouse wax synthase towards 14:0CoA. Myristic acid (14:0) is a very minor component of yeast lipids (around $2 \%$; data not presented), but in the produced wax esters (when yeasts carrying mouse wax synthase were fed exogenously with palmitoleic alcohol) it constitutes about $9 \%$ of their fatty acids component. The obtained results concerning the substrate specificity of mouse wax synthase are in agreement with the results obtained by Cheng \& Russel (2004). In their study with HEK 293 cells overexpressing mouse wax synthase, it was shown that the enzyme utilized a broad range of fatty alcohols and had preferences for saturated acyl-CoAs with 10-16 carbons, and unsaturated acyl-CoAs with 16-20 carbons. However, they did not perform quantitative analyses of mouse wax synthase products, so their results could be considered only as indicative ones.

The results of the study on the possibility of using different wax synthases for biodiesel production also showed that mouse WS can accept a broad range of fatty alcohols, using 16:0-CoA as the acyl donor (Shi et al., 2012). However, the activity of mouse WS (in cell-free yeast extracts) measured by the mentioned authors was 100-fold lower than the activity observed in the assays presented in this paper.
Final proprieties of wax esters depend on both their components: fatty acids and fatty alcohols. Therefore, a proper fatty acyl-CoA reductase (FAR) should complement wax synthase in future transgenic oilseed plants, in order to produce desired wax esters. In our study, we have shown that mouse wax synthase can utilize a broad range of fatty alcohols (towards the fatty acid component it showed narrower specificity). Thus, in future engineering of oilseed plants, the utilization of mouse wax synthase allows for a broader selection of different fatty alcohol components for the designed wax esters, compared with the fatty acid component.

The co-expression of mouse fatty acyl-CoA reductase and mouse wax synthase in fae 1 and fae 2 Arabidopsis double mutant, rich with oleic acids, enabled the formation of wax esters containing more than $65 \%$ of oleyl-oleate. The remaining fatty acid components of synthesized wax esters contained 18:1, 18:2 and 18:3 fatty acids, what reflects fatty acid composition of seed lipids (Heilmann et al., 2012). In the presented study we have shown that mouse WS accepted the 18:1-CoA fairly well, in combination with several fatty alcohols (Fig. 6). Thus, it is not surprising that oleate-oleate was the dominant wax ester in the mentioned transgenic seeds. The results of Heilmann et al. (2012) also showed that for the production of desired wax esters in transgenic plants, the composition of endogenous substrates available for enzymes connected with wax esters synthesis (FARs, WSs) is as important as the substrate specificity of these enzymes. In these seeds, wax esters with 14:0 or 16:0 fatty acid components were in absolute minority, whereas mouse WS expressed high preferences towards these fatty acids.

\section{Acknowledgements}

This work was supported by the European Commission through the FP7 ICON project.

The authors would also like to thank Professor Sten Stymne from the Swedish University of Agricultural Science for his comprehensive help throughout this research, and Dr. Peter Denolf from Bayer Crop Science NV (Ghent, Belgium) for providing plasmid constructs.

\section{REFERENCES}

Banas A, Dahlqvist A, Ståhl U, Lenman M, Stymne S (2000) The involvement of phospholipid:diacylglycerol acyltransferases in triacylglycerol production. Biochem Soc Trans 28: 703-705.

Table 2. Fatty acid composition of wax esters extracted from yeast expressing mouse WS gene.

\begin{tabular}{lllllll}
\hline Fatty acid [mol\%] & \multicolumn{1}{l}{} & & & \\
\hline $12: 0$ & $14: 0$ & $16: 0$ & $16: 1$ & $18: 0$ & $18: 1$ & $18: 1 \Delta 11$ \\
\hline $2.2 \pm 0.6$ & $9.1 \pm 0.3$ & $16.3 \pm 1.9$ & $53.1 \pm 2.5$ & $3.7 \pm 0.9$ & $13.7 \pm 0.9$ & $1.9 \pm 0.04$ \\
\hline
\end{tabular}

Mean values \pm standard deviation $(n=4)$ are shown; Yeast was grown on the medium with $16: 0-\mathrm{OH}$. The only fatty alcohol component of the analyzed wax esters was 16:0-OH.

Table 3. DGAT activity in microsomal preparations of control and carrying mouse WS yeast.

\begin{tabular}{|c|c|c|}
\hline \multirow{2}{*}{ Substrates } & \multicolumn{2}{|c|}{$\mathrm{nmol}\left[{ }^{14} \mathrm{C}\right]$ TAG formed/min $\mathrm{xmg}$ protein } \\
\hline & control yeast & yeast carrying mouse WS \\
\hline$\left[{ }^{14} \mathrm{C}\right] \mathrm{di}-18: 1-\mathrm{DAG}-14: 0-\mathrm{CoA}$ & $0.08 \pm 0.02$ & $0.11 \pm 0.01$ \\
\hline$\left[{ }^{14} \mathrm{C}\right] \mathrm{di}-18: 1-\mathrm{DAG}-16: 0-\mathrm{CoA}$ & $0.04 \pm 0.00$ & $0.10 \pm 0.01$ \\
\hline$\left[{ }^{14} \mathrm{C}\right] \mathrm{di}-18: 1-\mathrm{DAG}-18: 1-\mathrm{CoA}$ & $0.09 \pm 0.01$ & $0.16 \pm 0.01$ \\
\hline$\left[{ }^{14} \mathrm{C}\right] \mathrm{di}-18: 1-\mathrm{DAG}-22: 1-\mathrm{CoA}$ & $0.04 \pm 0.01$ & $0.07 \pm 0.01$ \\
\hline
\end{tabular}


Biester EM, Hellenbrand J, Gruber J, Hamberg M, Frentzen M (2012) Identification of avian wax synthases. BMC Biochem 13:4, doi: 10.1186/1471-2091-13-4.

Bligh EG, Dyer WJ (1959) A rapid method of total lipid extraction and purification. Can J Med Sci 37: 911-91.

Cheng J B, Russell D W (2004) Mammalian wax biosynthesis. II. Expression cloning of wax synthase cDNAs encoding a member of the acyltransferase enzyme family. I Biol Chem 279: 37798-37807.

Dahlqvist A, Ståhl U, Lenman M, Banaś A, Lee M, Sandager L, Ronne H, Stymne S (2000) Phospholipid:diacylglycerol acyltransferase: an enzyme that catalyzes the acyl-CoA-independent formation of triacylglycerol in yeast and plants. Proc Natl Acad Sci USA 97: 64876492.

Gietz RD, Woods RA (2002) Transformation of yeast by lithium acetate/single-stranded carrier DNA/polyethylene glycol method. Methods Ensymol 350: 87-96.

Heilmann M, Iven T, Ahmann K, Hornung E, Stymne S, Feussner I (2012) Production of wax esters in plant seed oils by oleosomal cotargeting of biosynthetic enzymes. J Lipid Res 53: 2153-2161.

Holtzapple E, Schmidt-Dannert C (2007) Biosynthesis of isoprenoid wax ester in Marinobacter hydrocarbonoclasticus DSM 8798: identification and characterization of isoprenoid coenzyme A synthetase and wax ester synthases. J Bacteriol 189: 3804-3812.

Kalscheuer R, Steinbüchel A (2003) A novel bifunctional wax ester synthase/acyl-CoA:diacylglycerol acyltransferase mediates wax ester and triacylglycerol biosynthesis in Acinetobacter calcoaceticus ADP1.J Biol Chem 278: 8075-8082.

Klypina N, Hanson S (2008) Arabidopsis thaliana wax synthase gene homologues show diverse expression patterns that suggest a specialized role for these genes in reproductive organs. Plant Sci 175: 312-320.

Lardizabal K D, Metz JG, Sakamoto T, Hutton W C, Pollard M R, Lassner M W (2000) Purification of a jojoba embryo wax synthase, cloning of its cDNA, and production of high levels of wax in seeds of transgenic Arabidopsis. Plant Physiol 122: 645-655.

Lassner MW, Lardizabal K, Metz JG (1999) Producing wax esters in transgenic plants by expression of genes derived from jojoba. Per- spectives on new crops and new uses Janick J ed, pp 220-224. ASHS Press, Alexandria, VA.

Li F, Wu X, Lam P, Bird D, Zheng H, Samuels L, Jetter R, Kunst L (2008). Identification of the wax ester synthase/acyl-coenzyme A:diacylglycerol acyltransferase WSD1 required for stem wax ester biosynthesis in Arabidopsis. Plant Physiology 148: 97-107.

Lu C, Clemente TE, Cahoon E (2010). Camelina sativa as a platform for the production of oils with enhanced lubricant properties. 19th International Symposium on Plant Lipids. Cairns, Australia.

Miwa TK (1971). Jojoba oil wax esters and derived fatty acids and alcohols - Gas chromatographic analyses. J Am Oil Chem Soc 48: 259-264.

Sánchez M, Nicholls DG, Brindley DN (1973) The relationship between palmitoyl-coenzyme A synthetase activity and esterification of sn-glycerol 3-phosphate in rat liver mitochondria. Biochem J 132: 697-706.

Sandager L, Gustavsson MH, Stahl U, Dahlqvist A, Wiberg E, Banas A, Lenman M, Ronne H, Stymne S (2002) Storage lipid synthesis is nonessential in yeast. J Biol Chem 277: 6478-6482.

Shi S, Valle-Rodríguez JO, Khoomrung S, Siewers V, Nielsen V (2012) Functional expression and characterization of five wax ester synthases in Saccharomyces cerevisiae and their utility for biodiesel production. Biotechnology for Biofuels 5: 7 (Open Access; http://www.biotechnologyforbiofuels.com/content/5/1/7).

Ståhl U, Carlsson A, Lenman M, Dahlqvist A, Huang B, Banas W, Banas, A., Stymne, S. (2004) Cloning and functional characterization of a phospholipid:diacylglycerol acyltransferase from Arabidopsis. Plant Physiol 135: 1324-1335.

Stöveken T, Kalscheuer R, Malkus U, Reichelt R, Steinbüchel A (2005) The wax ester synthase/acyl coenzyme A:diacylglycerol acyltransferase from Acinetobacter sp. strain ADP1: characterization of a novel type of acyltransferase. J Bacteriol 187: 1369-1376.

Teerawanichpan P, Qiu X (2010). Fatty acyl-CoA reductase and wax synthase from Euglena gracilis in the biosynthesis of medium-chain wax esters. Lipids 45: 263-273. 